\title{
Defining Research Priorities in Nutrition in a Resource Limited Setting a Delphi Study in Pakistan
}

\author{
Iftikhar Alam ${ }^{1 *}$, Atta Ulllah Jan ${ }^{1}$, Muhammad Ali' ${ }^{2}$ and Muhammad Farooq ${ }^{3}$
}

${ }^{1}$ Department of Human Nutrition \& Dietetics, Bacha Khan University, Charsadda, KPK, Pakistan; ${ }^{2}$ Department of Biotechnology, Bacha Khan University, Charsadda, KPK, Pakistan; ${ }^{3}$ College of Food Science and Engineering, Northwest AEFF University, Yangling, Shaanxi, 712100, PR China.

\begin{abstract}
Data on priority research areas are scarce such that decision making on the types of research in nutrition is tough both for researchers and health policy makers. Defining research priorities is important for proper planning in nutrition. The objective of the present study was to identify most important nutrition research areas of the highest priority in order to be more focused on decision making issues concerning nutrition research promotion. This study was descriptive in nature and utilized a three-round Delphi technique to identify and make consensus on opinions regarding priority research areas from experts in the field of nutrition. The initial questionnaire for 'Round one' consisted of single-open-ended, asking the experts to identify at least five most important nutrition research areas. Consequent upon repeated consensus building process, the experts identified and agreed upon ten most important nutrition research areas. The three most important of these, as rated by participants, were: undernutrition and its determinants, factors and nutritional determinants of low birth weight (LBW), and factors and nutritional determinants of stunting and wasting. These priorities should direct future research activities in the field and be reflected in research policies of the country. We recommend larger research studies also including more diverse experts' opinion.

Received | February 27,2021; Accepted | March 28, 2021; Published | May 28, 2021

*Correspondence | Iftikhar Alam, Department of Human Nutrition \& Dietetics, Bacha Khan University, Charsadda, KPK, Pakistan; Email: iftikharalam@bkuc.edu.pk

Citation | Alam, I., A.U. Jan, M. Ali and M. Farooq. 2021. defining research priorities in nutrition in a resource limited setting a Delphi study in Pakistan. Journal of Innovative Sciences, 7(1): 121-127.

DOI | https://dx.doi.org/10.17582/journal.jis/2021/7.1.121.127

Keywords | Research priorities in nutrition, Pakistan, Nutritional problems
\end{abstract}

\section{Introduction}

$\mathrm{N}$ utrition is an ultimate necessity for sustenance of life and maintenance of good health and functional integrity of the living body (Lange, 2017; Mann and Truswell,2017; Truswell,2017).In addition, the science of nutrition holds importance for its role towards solution of a number of issues concerning numerous challenges to environment, economy, community and society (Ohlhorst et al., 2013; Donini et al., 2017; Mann and Truswell,2017; Mocciaro et al.,
2017). (Truswell, 2017; Ohlhorst et al., 2013; Donini et al., 2017; Mocciaro et al., 2017). Research activities in nutrition sciences has been, therefore, under debate and discussion within the academicians, researchers, and health policy-makers. The main question is what are the most pressing challenges and problems that need to be addressed as areas of nutrition research. As a general guide, the research priorities should align with the corresponding disease burden confronting the population (Freire, 2005; Donini et al., 2017; Rice et al., 2017; GFHR, 2004; WHO, 2001; Bloom et al., 
2006), this is in fact desirable in order to augment the efficiency and effectiveness of particular actions that are needed for the improvement of health.

Like in many other developing societies, nutrition is also an emerging science in Pakistan (Mansoor, 2015, 2017; Badrruddin and Inam, 2020) and only few universities offer degree programs in this particular discipline (Khandelwal et al., 2014). There are even trivial number of research institutes that do research work in nutrition. Pakistan is a poor developing economy and research is not on the priority list of its national development agenda. It is logical to assume that Pakistan can hardly allocate only small budgets for research work, particularly, in nutrition. It, therefore, becomes even more imperative to determine which research areas in nutrition should be prioritized narrowly specifying the focus. No doubt this is a watchful task and needs both immense nutrition know-how and a realistic approach. We, therefore, conducted a pilot study involving experts in the field of nutrition using the Delphi technique to investigate what are those particular areas, keeping in view the available meagre research resources, little budget allocations and relatively insignificant research capacity in nutrition. A clear research priorities articulation and pronunciation will be of benefit to the nutrition research community an initiative that is very likely to lead to science-based information and that will be of enormous assistance in shaping nutrition policy and enhancing future funding opportunities for nutrition research, and thereby further promoting the nutrition sciences in Pakistan.

\section{Materials and Methods}

The Delphi consensus technique was selected as it has been extensively used in other health allied sciences (Cox et al., 2009, 2010; Rankin et al., 2012; Rushton et al., 2014). We have recently successfully used the technique in our investigations (e.g. Alam et al., 2017).

A working group of experts was constituted. This was mainly comprising researchers and professors in Human Nutrition from various universities of Pakistan. A workshop was conducted in 2017. In this workshop, the working group identified ten core areas of research through an extensive review of literature. Sub-areas of nutrition research under these ten core areas were decided to be identified following the Delphi technique. As a first step for a Delphi technique, a final expert panel $(n=28)$ was selected by identifying them on the internet and included individuals from diverse fields i.e., nutrition academicians, dieticians and nutritionists and researchers. Characteristics of the expert panel are given in Table 1.

Table 1: Basic characteristics of the expert panel.

\begin{tabular}{llll}
\hline $\begin{array}{l}\text { Field of expertise } \\
\text { (n) }\end{array}$ & $\begin{array}{l}\text { Age in } \\
\text { years (std) }\end{array}$ & $\begin{array}{l}\text { Terminal } \\
\text { degree }\end{array}$ & $\begin{array}{l}\text { Mean experience } \\
\text { in years (std) }\end{array}$ \\
\hline $\begin{array}{l}\text { Nutrition } \\
\text { Academicians (6) }\end{array}$ & $55.6(11.6)$ & $\mathrm{PhD}$ & $12.3(3.5)$ \\
$\begin{array}{l}\text { Dietarians/ } \\
\text { Nutritionists (7) }\end{array}$ & $47.3(5.7)$ & $\mathrm{PhD} / \mathrm{RD}$ & $11.2(5.2)$ \\
$\begin{array}{l}\text { Nutrition } \\
\text { Researchers (7) }\end{array}$ & $53.7(7.8)$ & $\mathrm{PhD}$ & $14(7.4)$ \\
$\begin{array}{l}\text { Public Health } \\
\text { Experts (5) }\end{array}$ & $51.9(3.2)$ & $\mathrm{PhD}$ & $16(3.8)$ \\
$\begin{array}{l}\text { Nutrition } \\
\text { Curriculum (3) }\end{array}$ & $49(5.7)$ & $\mathrm{PhD}$ & $15.2(6.9)$ \\
\hline
\end{tabular}

\subsection{Procedure of data collection}

Round 1: This round required panel members to list up to five research priorities in nutrition for research professionals. An open-ended question was mailed to the experts. The question was: What in your opinion, are the most important of the maximum priority areas of nutrition research in the context of Pakistan? The responses from the experts were analysed and a list of research priority areas was prepared and sent to the panel for the second round consensus.

Round 2: This round required participants to rate the importance of each research topic using a (1-4 Likert) scale. Experts' responses were received and analysed for round 3 .

Round 3: This round provided participants with a list of those research topics which had reached consensus during Round 2, along with their supporting statements, and the panel members were enquired to rate each research priority area once again. Round 3 scores were considered final.

The procedure is summarized in Figure 1.

\subsection{Statistical analysis}

All the data were captured on an Excel spreadsheet (MS Office, 2013) and imported to and analyzed by GraphPad Prsim Software (Version-7; GraphPad Prism Inc., USA). For all the responses received, we calculate means with standard deviation (SD). Frequency of responses reporting 3 (=Agree) plus 4 
(=Strongly Agree) $\left(\mathrm{f}^{3+4}\right)$ were also calculated. To get an overall consensus and support for a statement, we used means that allow to get numerical indications of consensus on a scale from 1 to 4 for measuring the responses on the statements. Mean values between 2 and 3 indicated uncertainty; while 3.5 and 1 indicated positive and negative certainty, respectively. A mean rating of $\geq 3.0$ and/or $\mathrm{f}^{3+4} \geq 75 \%$; the latter signifies $\geq 3 / 4^{\text {th }}$ agreement of the panel members with scoring 3 and/plus 4 , respectively for 'Important' or 'Very Important' on the Likert scale. For the present study, consensus was considered to be established on a statement with a mean rating of $\geq 3.0$; a coefficient of variation $(\mathrm{CV} \%)$ of $\leq 30 \%$, and $\mathrm{f}^{3+4} \geq 75 \%$ (signifies that $\geq 3 / 4^{\text {th }}$ or $\geq 75 \%$ of panel members scoring ' 3 ' $=$ important or ' 4 ' $=$ very important on the Likert scale).

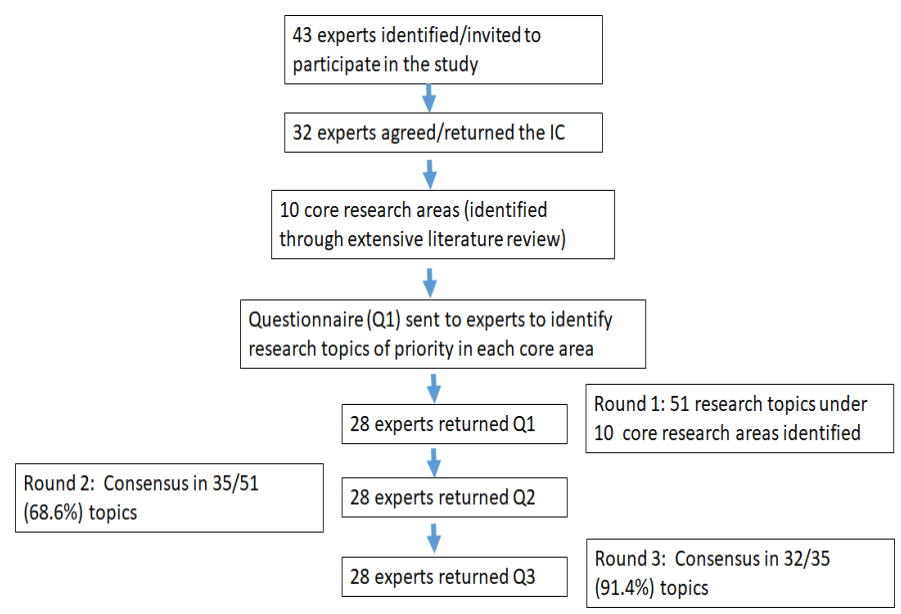

Figure 1: Flow chart showing the procedure of Delphi technique used.

\section{Results and Discussion}

The main objective of the present research was to determine research priorities in nutrition in an effort to narrow down the scope of nutrition research for researchers in a resource limited country like Pakistan. For this purpose, an expert panel $(n=28)$ was requested to part their judgement in ascertaining research priority areas in nutrition for Pakistan. The Delphi technique was used in the current study. This method has been extensively used in situations for consensus building (Rushton et al.,2014; Rankin et al.,2012; Cox et al., 2009). Round 1 required panel members to list up to five research topics of priorities in nutrition for research for each of ten core areas already identified. An open-ended question was mailed to the experts. The question was: What in your opinion, are the most important of the maximum priority areas of nutrition research in the context of Pakistan? Round 2 required participants to rate the importance of each research topic using a (1-4 Likert) scale. Round 3 provided participants with a list of those research topics which had reached consensus during Round 2, along with their supporting statements, and panel members were enquired to rate each research priority area once again. Round 3 scores were considered final.

Table 2 shows the results after Round 3 was completed and a general consensus on priority research areas was achieved. In Round 1, we received nineteen research areas in nutrition with their comments from the experts in the form of statements (Data no shown). We analyse the data and rephrased and/or reworded each statement without changing its meaning. We also added three research areas based on our own observations and in this way a total twenty-one research areas were forwarded to the experts for scoring in Round 2. The analysis of the data from Round 2 suggested to retain ten (out of twenty one) research priority areas. Eleven areas were excluded because their consensus could not establish on them (for consensus, a mean rating of $\geq 3.0$; a $C V \%$ of $\leq 30 \%$, and $\mathrm{f}^{3+4} \geq 75 \%$ was needed). The ten research areas were forwarded to the exports for final consensus and approval. The results of Round 3 suggest these ten areas be retained and considered as the areas of research priority in nutrition.

Defining research priorities provides strategic direction for nutrition researchers who want to apply for research funds, as well as communicating to funders the key/emerging research priorities for the profession. Defining research priorities also provide the policy makers with an unambiguous assistance in decision making for allocating funds and budgets to research activities.

The present study identified ten broad areas of research priorities for Pakistan. These are important areas as already a substantial volume of published literature has reported these issues which means these are the important areas for focusing further research. Previous research data suggest that there are enormous knowledge gapes in these areas. Undernutrition is common in Pakistan (Shah et al., 2003; Sachdev, 2001) and investigating its determinants is important for preventive measures. Low birth weight (Janjua et al., 2009; Lone et al., 2004; Sachdev, 2001), stunting (Shah et al., 2003; Khuwaja et al., 2005), micronutrient deficiencies 
Table 2: Mean scores, coefficient of variance and frequency of responders with score 3 plus 4 .

1. Under-nutrition and its main determinants:

$\begin{array}{llll}50 & 4.0 & 100 & 8\end{array}$

Cross-sectional studies that evaluate the prevalence/etiology of under-nutrition

Studies that develop or evaluate various growth charts (e.g. weight-for-age; weight for height, etc)

Studies that identify the "methods of diagnosis" for the assessment of the effect of nutrition on development and growth, assessment of energy expenditure, BMR, etc in children.

Studies that investigate the effect of various infections (measles, intestinal parasites, infectious diarrhea, pneumonia) on nutrition.

2. Factors and Nutritional Determinants of Low birth weight (LBW):

Studies considering maternal nutrition issues in pregnancy in relation to LBW.

Studies that consider maternal nutrition in lactation in relation to LBW

Studies that consider maternal nutrition in adolescent pregnancy and lactation relation to LBW

Studies that relate to the assessment of intrauterine growth in relation to nutrition and those involving nutrition of LBW and preterm infants

Studies of other social, environmental factors relevant to nutrition in relation to LBW

3. Stunting (Stunt):

Cross-sectional studies that evaluate the prevalence/etiology of stunting

Research studies that relate stunting in children to causes and consequences of nutrition.

Studies of other social, environmental factors relevant to nutrition in relation to stunting

4. Micronutrient Nutrition:

Cross-sectional studies that evaluate the prevalence/etiology of micronutrient deficiencies in all population segments with a consideration of their geographical distribution

Studies referring to micronutrient deficiencies, irrespective of whether there is any other possible linkages to other common nutritional disorders/problems (i.e. studies on LBW and iron were classified as micronutrient).

Studies with solution approaches (i.e., how to combat MDs, easier tools, bio-fortification, fortification at household level, dietary diversification etc).

5. Lactation and breast-feeding (BF):

Research studies that relate nutrition to lactation and breast-feeding.

Research studies that investigate effects of breastfeeding on mothers as well as children (effects: cognition, scholastic, social, behavior, physical, physiological)

6. Obesity/nutrition-related chronic disease (NRCD):

Cross-sectional studies that evaluate the prevalence/etiology of obesity

Research studies relating to fat intake, food habits, life style that leads to obesity, lipid profiles, oxidative stress, salt intake and free radicals

Studies that relate obesity and functional foods

Studies that relate obesity and life style and obesity and nutrition (e.g. physical activity, dietary fibre and obesity, antioxidants, body fat composition; including pre- and probiotics).

Research Studies that relate obesity with other nutrition problem (i.e. gestational diabetes, diabetes type I and II, insulin resistance, metabolic syndrome, cardiovascular diseases, hypertension etc).

Studies that investigate the evaluated nutritional risk factors that lead to NRCD in childhood and

adolescent age.

Study that investigate the inflammatory effects of diets

Study that investigate the causes of central obesity in adults

Evaluation of obesegenic environment in relation to obesity

7. Nutrition policy and framework:

Studies that consider how to develop research-based nutrition policy

Nutrition security assessment, prevalence, etiology etc

8. Portion and serving sizes:

Studies to standardize the portion sizes

9. Nutrition of the elderly:

Research studies related to aging

Research studies how nutrition speeds up aging, how to prevent premature aging with nutrition

10. Nutrition status indicators (NSI):

Studies that try to find out new and more sensitive, validated local NSI and biomarkers

$\mathrm{f}^{3+4 *}=$ Percent number (frequency) of responders who score 3 or 4 . The \%age shows the $\%$ sum of the responders. $\mathrm{CV}^{* *}=$ coefficient of variance (Note: The coefficient of variation $(\mathrm{CV})$ gives a simple ratio between the standard deviation and its corresponding mean across the expert panelists). 
(Harding et al., 2017; Abdullah et al., 2017; Soofi et al., 2013) are also some of the nutritional problems extensively reported. Similarly, nutrition in relation to lactation and breastfeeding complications (Bhandari et al., 2008; Bhutta, 2000; Hanif, 2011) and obesity and its related chronic diseases (Jaffar, 2006; Nanan, 2002; Misra and Khuran, 2011) have been the other extensively reported nutritional problems widely prevalent in Pakistan. Very meager, if any, data are available on nutrition policy and framework (e.g. Zaidi et al., 2013; Warraich et al., 2009), and this area needs particular research highlighting. There have been only scarce research studies on nutrition-related issues of the elderly (Alam et al., 2012a, b), despite the fact that Pakistan is also passing the age-nutrition transition (Alam et al.,2012a), and research in geriatric nutrition needs particular attention. Some nutrition research capacities like food composition database and country own specific nutrition indicators for Pakistan are essentially missing and wanting (Alam et al., 2012a), and there is specific research emphasis compulsory on these areas.

In conclusion, we express our confidence that these areas of priority in nutrition research, though not exclusive, mainly cover the research priority areas of most academic and research institutes of Pakistan. We also have the optimism that the findings from the current research study will help in stimulating adaptation and hence development of novel, innovative but feasible approaches that may be applied in treatment, but most importantly, the prevention of a wide range of nutrition diseases, a snapshot of that is presented in Table 2. Nutrition research is multidisciplinary in its very nature requiring a diverse group of stakeholders from diverse areas of their expertise to collaborate on complex and multifaceted lines to form the evidence-based nutrition policies and guidance that will direct to better health. In addition to the research priority areas and needs identified in the present investigation, we also feel it necessity to recognize those tools critical for the progress and advancement of the nutrition research needs in Pakistan. In the face of the fact of dwindling resources and the competing priorities, the prioritizing nutrition research provides an opportunity of more focusing on the future research that can positively and economically impact health. Research priorities in nutrition will cover the full scope of nutrition sciences focusing on providing better solutions to a wide range of health-related issues, rather than just one issue in particular. Finally, we recommend more extensive and elaborated studies by including experts from the national as well as international spheres working in diverse fields are needed. In this way, we will be able to cover priority areas in nutrition research where people from other scientific domains are also interested.

\section{Novelty Statement}

The present study will very helpful for character nutritionist and food scientist.

\section{Author's Contribution}

Iftikhar Alam: Conceptualization, methodology, formal analysis, writing-original draft.

Muhammad Ali and Atta Ullah Jan: Help in methodology section.

Muhammad Farooq: Conceptualization, review the manuscript \& amp; editing.

Conflict of interest

The authors have declared no conflict of interest.

\section{References}

Abdullah, M., Mahmood, S. and Ahmed, Z., 2017. Efficacy studies of natural and synthetic iron sources among anemic pregnant women in community of Faisalabad-Pakistan. Journal of Food and Nutrition Research, 5(2): 121-128.

Alam, I, Jan, A., Noushad, S. and Haq, Z., 2017. Curriculum for BS study program in nutrition and dietetics. Assessment and Evaluation. International Journal of Endorsing Health Science Research. 5(3): 4-16. https://doi.org/10.29052/ IJEHSR.v5.i3.2017.04-16

Alam, I., Larbi, A. and Pawelec, G., 2012. Nutritional status influences peripheral immune cell phenotypes in healthy men in rural Pakistan. Immunity and Ageing. 9(1): 16. https://doi.org/10.1186/1742-4933-9-16

Alam, I. and Pawelec, G., 2012. Aging, nutrition and immunity-their relationship and interaction. Nutrition and Aging., 1(3, 4): 151-165. https:// doi.org/10.3233/NUA-130013

Badruddin, S.H. and Inam, S.N., 2020. Nutrition education in the undergraduate medical curriculum at the Aga Khan University, Karachi, Pakistan. JPMA. The Journal of the Pakistan Medical Association, 52(8): 364-367. 
Bhandari, N., Kabir, A.K. and Salam, M.A., 2008. Mainstreaming nutrition into maternal and child health programmes: scaling up of exclusive breastfeeding. Maternal and Child Nutrition, 4(s1): 5-23. https://doi.org/10.1111/ j.1740-8709.2007.00126.x

Bhutta, Z.A., 2000. Iron and zinc intake from complementary foods: Some issues from Pakistan. Pediatrics, 106(Supplement 4): 12951297.

Bloom, B.R., Michaud, C.M., La Montagne, J.R. and Simonsen, L., 2006. Priorities for global research and development of interventions. In: Jamison, D.T., Breman, J.G., Measham, A.R., Alleyne, G., Claeson, M., Evans, D.B., et al., eds. Disease Control Priorities in Developing Countries, 2nd ed. Washington, DC: The World Bank and Oxford University Press, pp. 103-118.

Cox, J., Halkett, G., Anderson, C. and Heard, R., 2010. A Delphi study on research priorities in radiation therapy: The Australian perspective. Radiography, 16(1): 26-39. https://doi. org/10.1016/j.radi.2009.09.006

Donini, L.M., Leonardi, F., Rondanelli, M., Banderali, G., Battino, M., Bertoli, E., Bordoni, A., Brighenti, F., Caccialanza, R., Cairella, G. and Caretto, A., 2017. The domains of human nutrition: The importance of nutrition education in academia and medical schools. Frontiers in Nutrition, pp. 4. https://doi.org/10.3389/ fnut.2017.00002

Freire, W.B., 2005. Nutrition and an active life: From knowledge to action. Scientific and technical publication no. 612. Washington, DC: Pan American Health Organization.

GFHR. Global Forum for Health Research (GFHR). 2004. 10/90 report on health research 2003-2004. Report No. 4. Geneva: GFRH, 10 May 2004.

Hanif, H.M., 2011. Trends in breastfeeding and complementary feeding practices in Pakistan, 1990-2007. International Breastfeeding Journal. 6(1): 15. https://doi.org/10.1186/1746-4358-6-15

Harding, K.L., Aguayo, V.M., Namirembe, G. and Webb, P., 2017. Determinants of anemia among women and children in Nepal and Pakistan: An analysis of recent national survey data. Maternal and Child Nutrition. https://doi.org/10.1111/ men.12478

Jafar, T.H., 2006. Chaturvedi N, Pappas G.
Prevalence of overweight and obesity and their association with hypertension and diabetes mellitus in an Indo-Asian population. Canadian Medical Association Journal, 175(9): 1071-1077. https://doi.org/10.1503/cmaj.060464

Janjua, N.Z., Delzell, E., Larson, R.R., Meleth, S., Kristensen, S., Kabagambe, E., Sathiakumar, N., 2009. Determinants of low birth weight in urban Pakistan. Public Health Nutrition, 12(6): 789798. https://doi.org/10.1017/S1368980008002942

Khandelwal, S., Paul, T., Haddad, L., Bhalla, S., Gillespie, S., Laxminarayan, R., 2014. Postgraduate education in nutrition in south Asia: a huge mismatch between investments and needs. BMC Medical Education, 14(1): 3. https://doi.org/10.1186/1472-6920-14-3

Khuwaja, S., Selwyn, B.J. and Shah, S.M., 2005. Prevalence and correlates of stunting among primary school children in rural areas of southern Pakistan. Journal of Tropical Pediatrics. 51(2): 72-77. https://doi.org/10.1093/tropej/ fmh067

Lange, K.W., 2017. Movement and nutrition in health and disease. Movement and Nutrition in Health and Disease. pp. 1.

Lone, F.W., Qureshi, R.N. and Emanuel, F., 2004. Maternal anaemia and its impact on perinatal outcome. Tropical Medicine and International Health, 9(4): 486-490. https://doi.org/10.1111/ j.1365-3156.2004.01222.x

Mahmood, H., Suleman, Y., Hazir, T., Akram, D.S., Uddin, S., Dibley, M.J., Abassi, S., Shakeel, A., Kazmi, N. and Thow, A.M., 2017. Overview of the infant and young child feeding policy environment in Pakistan: Federal, Sindh and Punjab context. BMC Public Health, 17(2): 474. https://doi.org/10.1186/s12889-017-4341-5.

Mann, J. and Truswell, S., 2017. Essentials of human nutrition. Oxford University Press.

Mansoor, S., 2017. Undergraduate medical students perceptions regarding nutrition education curriculum at Shifa College of Medicine. Isra Med. J., 9(2): 88-89

Mansoor, S., 2015. Nutrition education curriculum for training physicians in medical colleges of Pakistan. Pakistan Armed Forces Medical Journal, 63(3): 382-3853.

Misra, A. and Khurana, L., 2011. Obesity-related non-communicable diseases: South Asians vs White Caucasians. International Journal of Obesity, 35(2): 167. https://doi.org/10.1038/ 
ijo.2010.135

Mocciaro, G., Ziauddeen, N., Nicholson, S., Almoosawi, S. and Ray, S., 2017. Findings from a UK-Morocco training programme to improve capacity in nutrition surveillance, research and education. Public Health. 142: 208-211. https:// doi.org/10.1016/j.puhe.2016.10.022

Nanan, D.J., 2002. The obesity pandemicimplications for Pakistan. J. Pakistan Med., 52(342): 6-11.

Ohlhorst, S.D., Russell, R., Bier, D., Klurfeld, D.M., Li, Z., Mein, J.R., Milner, J., Ross, A.C., Stover, P. and Konopka, E., 2013. Nutrition research to affect food and a healthy life span. The Journal of Nutrition, 143(8): 1349-1354. https://doi. org/10.3945/jn.113.180638

Rankin, G., Rushton, A., Olver, P. and Moore, A., 2012. Chartered society of physiotherapy's identification of national research priorities for physiotherapy using a modified Delphi technique. Physiotherapy, 98(3): 260-272.https:// doi.org/10.1016/j.physio.2012.03.002

Rice, M., Franceschini, C., Wallerstein, N., Mercer, R., Cimmino, K., Rodriguez, L., Latinovic, L., Pliego, P., Rodríguez, J.O., Aguillón, G.L. and Groot, A.M., 2017. Healthy municipalities, cities and communities in Latin America: Strong Histories, Committed Futures. Healthy Cities, Springer New York. pp. 151-213. https://doi. org/10.1007/978-1-4939-6694-3_8

Rushton,A.B.,Fawkes, C.A.,Carnes, D. and Moore, A.P., 2014. A modified Delphi consensus study to identify UK osteopathic profession research priorities. Manual Therapy, 19(5): 445-452. https://doi.org/10.1016/j.math.2014.04.013

Sachdev, H.P.S., 2001. Low birth weight in South Asia. Int. J. Diab. Dev. Countries, 21(1): 13-29.

Shah, S.M., Selwyn, B.J., Luby, S., Merchant, A. and Bano, R., 2003. Prevalence and correlates of stunting among children in rural Pakistan. Pediatrics International. 45(1): 49-53. https://doi. org/10.1046/j.1442-200X.2003.01652.x

Soofi, S., Cousens, S., Iqbal, S.P., Akhund, T., Khan, J., Ahmed, I., Zaidi, A.K. and Bhutta, Z.A., 2013. Effect of provision of daily zinc and iron with several micronutrients on growth and morbidity among young children in Pakistan: A cluster-randomised trial. The Lancet, 382(9886): $29-40$.

Truswell, S., 2017. Mann and Truswell 2017. Oxford University Press. https://doi.org/10.1016/S01406736(13)60437-7

Warraich, H.J., Javed, F., Faraz-ul-Haq, M., Khawaja, F.B. and Saleem, S., 2009. Prevalence of obesity in school-going children of Karachi. PLoS One, 4(3): e4816. https://doi.org/10.1371/ journal.pone. 0004816

World Health Organization (WHO), 2001. Macroeconomics and health: Investing in health for economic development. Report of the Commission on Macroeconomics and Health Generva.

Zaidi, S., Mohmand, S.K., Hayat, N., Acosta, A.M. and Bhutta, Z.A., 2013. Nutrition policy in the post-devolution context in Pakistan: An analysis of provincial opportunities and barriers. IDS Bulletin, 44(3): 86-93. https://doi. org/10.1111/1759-5436.12035 